\title{
Mobile banking como novo canal de disseminação de informações e disponibilização de serviços: um teste da Teoria do Comportamento Planejado Decomposto
}

Deborah Oliveira Santos

Mestre em Administração pelo CEPEAD - UFMG. Consultora na empresa Indicador Consultores.. Professora no CEFET-MG e Fundação Dom Cabral.

Ricardo Teixeira Veiga

Professor associado da Universidade Federal de Minas Gerais. Professor permanente do Centro de Estudos de Lazer e Recreação/UFMG.

Sarah Ituassú Souza

Graduanda do curso de Turismo da UFMG.

Investigou-se os antecedentes atitudinais da intenção de uso do mobile banking por clientes bancários, adotandose a teoria do Comportamento Planejado Decomposto como referencial teórico. Na fase conclusiva da pesquisa, com 515 respondentes, aplicou-se a modelagem de equações estruturais. O modelo teórico foi sustentado empiricamente, porém necessita de aperfeiçoamentos. Cerca de $74 \%$ da variação na intenção de uso do mobile banking foi explicada pelo modelo, em que o construto segurança foi acrescentado.

Palavras-chave: Mobile banking; Teoria do Comportamento Planejado Decomposto; Atitude; Segurança. 


\title{
Mobile banking as a new channel of information spreading and a means of making new services availabe: a test of the Theory of Decomposed Planned Behavior
}

\begin{abstract}
The atitudinal antecedents of the intention of using mobile banking by bank customers were investigated, adopting the Theory of Decomposed Planned Behavior as theoretical framework. In the conclusive stage of the research, with 515 respondents, structural equation modeling was employed. The theoretical model had empirical support, but it needs improvements. About $74 \%$ of variation in the intention of using mobile banking was accounted by the model, in which the construct secutity was added.
\end{abstract}

Keywords: Mobile banking; Theory of Decomposed Planned Behavior; Attitude; Security.

Recebido em 09.10.2009 Aceito em 12.12.2011

\section{Introdução}

As mudanças tecnológicas têm impactado o funcionamento das organizações, proporcionando, muitas vezes, redução de custos e melhoria na qualidade dos produtos ou serviços. Como principal mudança, pode-se dizer que o contexto atual não se prende à existência de um local físico como condição para transações comerciais e relacionamentos. Prospera hoje o espaço virtual, em que produtos e serviços, com forte conteúdo informacional, podem ser comercializados e distribuídos, por meio de sistemas baseados na Internet. Nesse contexto, cabe falar sobre bem de informação, que é a categoria de produtos e serviços cuja fonte primária de valor e a disposição a pagar dos clientes residem nas informações ofertadas que, uma vez digitalizadas, podem ser dissociadas das embalagens físicas na qual são entregues (CARVALHO, 2004).

No Brasil, país em que o setor bancário é caracterizado por grandes investimentos em TI, a oferta de múltiplos canais de atendimento está consolidada. Essa constatação determinou a escolha deste setor para a realização deste estudo. Autores como Abdala (2004), ressaltam que o Brasil é um dos países onde os serviços bancários online foram rapidamente difundidos. Entre os recursos de TI utilizados como alternativas de acesso aos serviços bancários destacam-se: caixas 
eletrônicos, serviços por telefone, internet banking e, recentemente, o mobile banking.

A literatura sobre tecnologias bancárias desenvolveu-se, no Brasil, principalmente a partir do final da década de 1980. Recentemente, nas principais publicações do País, foram retratados vários estudos sobre a nova tecnologia do internet banking. Não se encontram com tanta facilidade, entretanto, estudos brasileiros sobre o tema "mobile banking". Percebe-se, portanto, a falta de estudos sobre a intenção dos potenciais usuários (clientes bancários) em utilizar essa nova tecnologia.

$\mathrm{Na}$ perspectiva do consumidor, para a utilização de um canal eletrônico, não basta o entendimento sobre o novo sistema de TI, fatores comportamentais precisam ser considerados. Existem algumas perspectivas teóricas que buscam entender os determinantes de adoção de uma tecnologia. A teoria utilizada neste estudo foi descrita por Taylor e Todd (1995). Os autores integraram conceitos de duas linhas de pesquisa: a teoria da difusão de inovações e a teoria do comportamento planejado, propondo um novo modelo, denominado "Teoria do comportamento planejado decomposto" (TCP Decomposto).

Com base nas abordagens teóricas sobre adoção de inovações, este estudo buscou analisar os antecedentes do comportamento de uma amostra de clientes bancários de Belo Horizonte, capital do estado de Minas Gerais. O objetivo do trabalho consistiu em verificar a validade da teoria do comportamento planejado decomposto para explicar a intenção dos clientes bancários em adotar o mobile banking como novo canal de interação com o banco.

\section{Referencial teórico}

\subsection{0 contexto das inovações tecnológicas na era da informação}

A utilização de novas tecnologias cria e recria novas formas de interação, novas identidades, novos hábitos sociais, enfim, novas formas de sociabilidade. É fácil perceber que o ambiente virtual e a comunicação propiciada pelas telecomunicações e pela Internet trouxeram novas características às organizações e diferentes formas de relacionamento com os clientes (ABDALA, 2004). As relações sociais já não ocorrem, necessariamente, pelo contato face a face entre os indivíduos. O emprego de tais tecnologias, sem dúvida, trouxe novas maneiras de comunicação, maior rapidez no acesso às informações e a possibilidade de transferência da informação em escala mundial (MORIGI; PAVAN, 2004).

Nesse sentido, mudanças têm sido vistas também na área da Ciência da Informação. Alguns estudos passados apresentavam a característica de serem centrados no sistema, ou seja, eram definidos em bases sociológicas, observando-se grupos de usuários. Atualmente, entretanto, acompanhando as novas tecnologias e tendências, as pesquisas estão cada vez mais centradas no indivíduo, buscando 
interpretar necessidades de informação tanto intelectuais, como sociológicas. Análises estão sendo feitas sobre as características únicas de cada usuário, buscando chegar às cognições comuns à maioria deles. A lógica básica subjacente a essa perspectiva centrada no usuário é que os sistemas de informação devam ser modelados de acordo suas necessidades de informação e seus padrões de comportamento na busca e no uso da informação, de modo a maximizar a eficiência dos processos (FERREIRA, 1995; FIGUEIREDO, 1990).

Em uma sociedade cada vez mais dependente dos sistemas de informação (MACMULLIN; TAYLOR, 1984), bancos e outros tipos de organizações, que operam em ambientes muito competitivos e lidam rotineiramente com grande volume de dados, procuram disponibilizar informações e serviços com, cada vez mais, menor intervenção humana direta (CHAIM, 2000). Com a automação bancária e desenvolvimento de serviços pela Internet, os benefícios de customização, conveniência e praticidade para o público, aliam-se a ganhos empresariais de redução de custos, aumento de capilaridade e integração de processos. Esses são resultados de elevados investimentos em TI, como no caso do Brasil, em que aumentaram $8 \%$ em 2007, relativamente ao ano anterior (FEBRABAN, 2008). De modo geral, o desenvolvimento da tecnologia bancária, desde a introdução do caixa eletrônico automático (ATM) até a oferta de serviços pela Internet, atesta a evolução a qual nos referimos.

\subsection{Mobile banking}

A indústria de telecomunicações encontra-se entre as áreas nas quais as mudanças têm sido cada vez mais velozes e intensas (PEREIRA; PAULA, 2001). Uma das consequências das inovações no setor de telecomunicações foi a difusão do telefone celular. Devido ao aumento de possibilidades tecnológicas e de recursos disponíveis nos aparelhos, o celular passou a representar um novo canal e, agora, um potencial para as relações de compra. No setor bancário, ao se visualizar o telefone celular como nova mídia e após a rápida difusão do internet banking, as instituições passaram a avaliar a possibilidade de autoatendimento pelo telefone celular.

O mobile banking é esse novo serviço bancário que possibilita aos clientes realizarem pelo celular quase todas as operações disponíveis em caixas de autoatendimento e internet banking. Correntistas podem consultar extratos e saldos, fazer transferências entre contas do banco, pagamentos de títulos e convênios, DOC/TED, recarga de celular pré-pago e empréstimos. Futuramente, os usuários poderão, também, fazer investimentos e resgates pelo mobile banking. A principal diferença entre internet banking e mobile banking é que na internet tem-se um modelo centrado no computador - ou seja, o usuário vai onde o computador está e ainda depende do acesso à rede. No caso do telefone celular, é o serviço que está onde quer que o usuário vá - ou seja, é um modelo centrado no usuário. 
Em geral, na perspectiva dos clientes, os fatores estão trabalhando pró e contra essa inovação. Por propiciar um contato direto, rico em informações e interativo, o novo canal permite maior facilidade de aquisição de informações por parte do cliente (ALBERTIN, 1999). Além disso, a falta de tempo dos clientes também incentiva o uso desses serviços e de novos canais (ALBERTIN, 1999). Porém, diversas pesquisas revelam a manifestação de sentimentos negativos de consumidores em relação a serviços que necessitem de interação com a tecnologia (SOUZA, 2002) e acabam por frear a difusão dessa inovação.

Segundo Rouse e Rouse (1984, p. 129), a busca por informação e o processo de tomada de decisão estão fortemente relacionadas com os hábitos pessoais do indivíduo e com as necessidades que precisam ser satisfeitas (BROWN, 1991). Dados os vários elementos influenciadores da decisão de utilização de uma nova tecnologia, teorias e modelos foram criados com a finalidade de proporcionar um entendimento maior das relações entre esses diversos fatores que interferem no processo de escolha.

\subsection{Comportamento do consumidor com relação à adoção e difusão de tecnologias}

O comportamento do consumidor é um campo de estudo que investiga os processos envolvidos na seleção, compra, utilização e disposição de produtos, serviços, ideias ou experiências pelos consumidores para satisfazer a suas necessidades e desejos (SOLOMON, 2002). Segundo Engel, Blackwell e Miniard (1995), o caso de adoção de nova tecnologia para lidar com finanças pessoais caracteriza uma compra inicial de alto envolvimento. As compras de alto envolvimento são definidas quando o processo de decisão é detalhado e rigoroso, no qual os custos e os riscos envolvidos na aquisição de produtos e serviços são grandes. Nesses casos, procedimentos de reflexão e avaliação geralmente precedem o ato de compra.

Apesar de existirem diferenças entre os diversos processos de compras, vários modelos que buscam entender o comportamento do consumidor foram desenvolvidos para descobrir como os consumidores combinam suas crenças e atitudes acerca de um objeto e como essas interferem no comportamento final de consumo. O modelo estudado neste trabalho pertence à perspectiva das teorias da ação, que são baseadas no pressuposto de que os seres humanos se comportam de forma racional e utilizam as informações que estão disponíveis, considerando as implicações de suas ações antes de decidirem (AJZEN, 2002). O objetivo central é tentar especificar os diferentes elementos que poderiam, juntos, influenciar as avaliações das pessoas sobre os objetos (SOLOMON, 2002). 


\subsubsection{Teoria do Comportamento Planejado Decomposto (TCPD)}

Com o objetivo de entender os determinantes de adoção de uma nova tecnologia, Taylor e Todd (1995) tentaram integrar duas perspectivas de estudo, propondo um novo modelo denominado "Teoria do Comportamento Planejado Decomposto" (TCP decomposto), a qual busca explorar e unir conceitos da teoria da difusão de inovações e teoria do Comportamento Planejado (TCP), que explica a intenção comportamental, a partir de antecedentes atitudinais (AJZEN, 1985).

Segundo Ajzen (2002), conforme a TCP, o comportamento humano é guiado por três tipos de crenças: crenças sobre as consequências prováveis de um comportamento (crenças comportamentais), crenças sobre as expectativas normativas de terceiros (crenças normativas) e crenças a respeito da presença de fatores que podem impedir ou facilitar a performance de um comportamento (crenças de controle). Crenças comportamentais produzem uma atitude favorável ou desfavorável em relação ao comportamento, crenças normativas resultam em pressão social perceptível ou norma subjetiva e crenças de controle podem facilitar ou impedir a performance de um comportamento. Em combinação, atitude em relação ao comportamento, norma subjetiva e percepção se o comportamento está sujeito à vontade, conduzem à formação de uma intenção comportamental. Como regra geral, quanto mais favoráveis são a atitude e a norma subjetiva e maior o controle percebido, maior deve ser a intenção pessoal de realizar o comportamento.

Assim, na TCP decomposto as antecedentes da intenção, são: atitude, normas subjetivas e controle percebido. O modelo, porém, busca também examinar uma variedade de fatores que se mostraram determinantes na taxa de difusão de inovações, segundo a teoria da difusão de inovações (IDT): vantagem relativa, compatibilidade, complexidade, observabilidade e testagem.

A TCP decomposto propõe a integração de duas linhas de pesquisas (Fig. 1). Assim, crenças atitudinais são decompostas em três construtos derivados da literatura sobre as características da inovação (ROGERS, 1983): utilidade percebida (vantagem relativa), facilidade de utilização (complexidade) e compatibilidade. As três variáveis são consideradas por Taylor e Todd (1995) como poderosas predecessoras das crenças de atitude.

Crenças normativas relacionam-se às opiniões entre os principais grupos de referência e muitos estudos têm sugerido a decomposição da estrutura das crenças normativas entre os relevantes grupos de referência.

Crenças de controle decompõem-se em dois grupos: autoeficácia e condições facilitadoras. A autoeficácia está relacionada à habilidade percebida de utilizar uma nova tecnologia; e condições facilitadoras referem-se à disponibilidade de recursos para realizar o comportamento. A decomposição das crenças de controle se refere à noção de que controle 
pode ser visto da perspectiva interna ao indivíduo ou externa (TAYLOR; TODD, 1995). A hipótese do modelo é que quanto maiores a percepção de autoeficácia no uso de uma nova tecnologia e de existência de condições facilitadoras maior será a intenção de adotar a inovação (TAYLOR; TODD, 1995).

Segundo Taylor e Todd (1995), essa decomposição, proposta na teoria, possibilita algumas vantagens, na medida em que torna as relações entre os construtos mais claras e compreensíveis. Além disso, é gerencialmente mais relevante, pois permite explicitar os fatores específicos que determinam a adoção e a utilização de uma nova tecnologia (HERNANDEZ; MAZZON, 2006). Como desvantagem, Taylor e Todd (1995) ressaltam a operacionalização do modelo, mais complexa que as teorias originais, pois engloba um número maior de variáveis.

Figura 1 - Teoria do Comportamento Planejado Decomposto

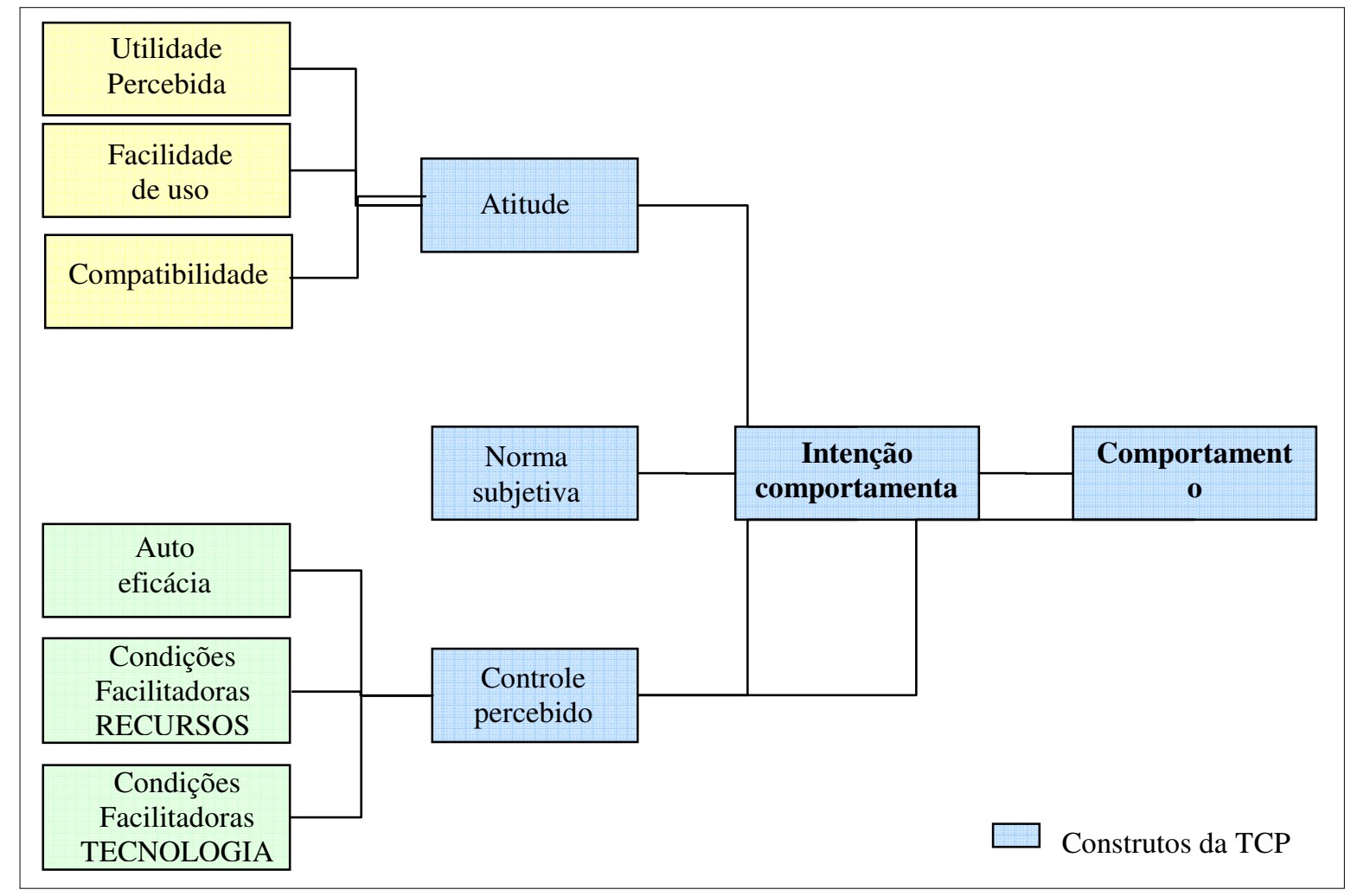

Fonte: Adaptado de TAYLOR; TODD (1995).

\subsection{Considerações sobre o marco teórico e hipóteses de pesquisa}

Visando contribuir para a compreensão da prontidão de adoção de um novo serviço bancário, este estudo testou a validade da Teoria do Comportamento Planejado Decomposto para explicar a intenção dos clientes de usar o mobile banking, como novo canal de interação com o banco. Foram elaboradas as seguintes hipóteses de pesquisa:

H1: Há um relacionamento positivo entre os construtos atitude e intenção comportamental; 
H2: Há um relacionamento positivo entre os construtos normas subjetivas e intenção comportamental;

H3: Há um relacionamento positivo entre os construtos controle percebido e intenção comportamental;

H4: Há um relacionamento positivo entre os construtos segurança e intenção comportamental. Essa hipótese somente foi incluída após a realização da análise de dados da etapa qualitativa, composta por entrevistas e grupo de foco, que demonstrou a necessidade de inclusão do construto segurança;

H5: A teoria do comportamento planejado decomposto possui poder explicativo para a adoção de novas tecnologias pelos consumidores;

H6: Há um relacionamento positivo entre os construtos controle percebido e comportamento real; e

H7: Há um relacionamento positivo entre os construtos intenção comportamental e comportamento real.

\section{Metodologia}

O foco deste estudo descritivo conclusivo (MALHOTRA, 2001) foi o estágio de adoção de tecnologia, etapa determinante para a aceitação e difusão de uma inovação. A população considerada, portanto, é constituída de indivíduos com perfil inovador, ou seja, pioneiros na adoção de novas tecnologias e agentes iniciais de sua difusão (ROGERS, 1983).

Segundo alguns autores, como Brasil (2006), o perfil de usuários inovadores é influenciado por idade, escolaridade e experiências com outras tecnologias. Brasil ressalta, ainda, que o "grau de instrução" constitui uma das variáveis mais consistentes para explicar variações no uso de canal de atendimento. Assim, concluiu-se que estudantes de pósgraduação lato sensu de Belo Horizonte poderiam constituir uma amostra possível para representar, aproximadamente, a população de potenciais usuários da tecnologia pesquisada.

A coleta de dados ocorreu em duas etapas complementares, uma qualitativa e outra quantitativa. Na etapa qualitativa, de finalidade exploratória, usaram-se as técnicas de entrevista não-estruturada e grupo focal.

Foram entrevistados vinte indivíduos, amostrados por conveniência, contatados em faculdades e em duas empresas que permitiram a coleta de dados. Todos os entrevistados possuíam conta corrente bancária, idade entre 25 e 35 anos, curso superior completo e experiência anterior com internet banking.

Conforme recomendações de especialistas (MALHOTRA, 2001), foram realizados três grupos focais. Os participantes foram recrutados através de contato com as instituições de ensino superior e via e-mail, fornecido por colegas e pessoas indicadas por eles. As discussões basearam-se em roteiro pré-estabelecido, fundamentado na TCPD. 
O objetivo da fase exploratória foi gerar insights sobre o tema pesquisado e apoiar a elaboração do questionário de pesquisa, utilizado na fase descritiva, em que se realizou um levantamento (survey).

A amostra do levantamento foi não-probabilística, por conveniência, e, portanto, é uma das limitações da pesquisa. O tamanho da amostra seguiu recomendações de Hair et al. (2005), que ressaltam que o tamanho absoluto mínimo deve obedecer à proporção mínima de cinco a dez respondentes para cada parâmetro estimado. Assim, para o presente estudo o número mínimo de amostra seria de 440 respondentes. Foram distribuídos 600 questionários, obtendo-se 515, posteriormente analisados estatisticamente.

\section{Análise dos dados}

\subsection{Fase I: análise de conteúdo}

Na análise das entrevistas e grupos de foco, adotou-se a técnica de análise de conteúdo, que visa à busca de sentido, possibilitando o tratamento, a análise, a interpretação dos dados (GODOY, 1995). A análise de conteúdo foi feita em duas etapas fundamentais, inspiradas em Bardin (2004): a pré-análise e a categorização. Na fase de categorização, foram elaboradas categorias, chamadas "categorias-síntese". Elas constituem um agrupamento de temas identificados nas falas dos participantes e que estão relacionados a um mesmo conteúdo, ainda que ditos de maneira diferente pelos indivíduos.

Para as entrevistas, não havia categorias previamente definidas, já que foram realizadas de forma não estruturada. Os resultados estão apresentados abaixo:

- canal de comunicação e relacionamento de fácil acesso: a urgência ou a necessidade imediata de realizar alguma transação bancária daria ao serviço mobile banking o status de ser o canal de relacionamento pensado como primeira opção, prioritário à Internet, porque é acessível em qualquer lugar;

- liberação de tempo: o serviço traz maior rapidez às operações, e por isso se configuraria como um serviço em que as pessoas "ganham" tempo. Esse foi o fator mais expressivo, de acordo com os entrevistados, para influenciar a utilização do serviço de mobile banking; e

- Dúvidas sobre a segurança: A falta de informações sobre o serviço e sobre como ocorrem as transações transmite a ideia de que o canal ainda não é totalmente confiável.

- quanto à análise dos resultados dos grupos de foco, foram feitas análises dos conteúdos manifestos nos três grupos realizados, porém, ao contrário das entrevistas, a categorização foi realizada com base em temas previamente elaborados. Essas categorias correspondem às variáveis presentes na teoria do comportamento planejado decomposto. 
- utilidade percebida no uso do mobile banking: as vantagens da nova tecnologia que revelaram consenso nos três grupos se relacionam a: comodidade, economia de tempo e rapidez das transações. Os grupos destacaram o ganho de tempo proporcionado pela nova tecnologia e a possível redução de gastos com deslocamento até uma agência bancária;

- compatibilidade da nova tecnologia com o estilo de vida e trabalho: com relação a este aspecto, não houve consenso em nenhum dos três grupos de foco realizados. Algumas pessoas relataram que o serviço é compatível com seus estilos de vida e de trabalho, que pressionam o indivíduo para atividades que evitem perda de tempo, enquanto outras não consideraram esse aspecto um fator significativo para influenciá-los na utilização da nova tecnologia;

- facilidade de uso: os grupos consideraram que o serviço de mobile banking é relativamente fácil de ser utilizado.;

- influência dos grupos de referência na tomada de decisão: do total de 27 participantes, 7 conheciam alguém de seu relacionamento que já utilizaram o mobile banking para a realização de transações bancárias. Em um consenso dos três grupos, os participantes disseram que as pessoas de seu relacionamento dificilmente agiriam para impulsionar ou formar uma intenção de uso do mobile banking. Afirmaram, entretanto, que a possibilidade de conhecer algum usuário e de vê-lo utilizando o sistema com sucesso, certamente os levaria a ter uma atitude mais favorável à utilização da nova tecnologia; e

- controle percebido para utilização do serviço: autoeficácia, tecnologia e recursos: o tópico abrange uma discussão sobre a percepção das pessoas sobre o controle que possuem para utilizar o novo serviço. Como anteriormente houve consenso com relação à percepção de facilidade de uso pelos participantes, a maioria também considerou a questão da autoeficácia algo bastante simples. O item "apoio para o uso da nova tecnologia", entretanto, foi bastante ressaltado. O outro aspecto discutido foram as condições facilitadoras para a adoção do mobile banking. No geral, os três grupos concordaram que os recursos tecnológicos e financeiros hoje não constituem barreira para a utilização do serviço. Segundo eles, o acesso a aparelhos e inovações ocorre como um processo acelerado. Além disso, os três grupos citaram os possíveis incentivos que podem surgir por parte das empresas de telefonia e bancos no intuito de reduzir os valores de acesso ao serviço. 
Além das categorias apresentadas, outros dois núcleos temáticos foram significativos durante as discussões e surgiram nos três grupos realizados:

- segurança oferecida pelo serviço: este tópico não é abordado diretamente pela TCP decomposto. Nos grupos, entretanto, esse foi um dos aspectos mais discutidos pelos participantes, que não conseguiram chegar a um consenso sobre a temática. A maioria dos participantes destacou a falta de segurança como um dos principais motivos para tomar uma decisão negativa ao uso do mobile banking; e

- ações para impulsionar o uso do mobile banking: os participantes citaram ações a serem tomadas para fazer com que atitude dos clientes com relação à utilização do serviço se tornasse favorável. As principais citações se referem à segurança e à facilidade de uso. Em geral, as pessoas sugeriram o desenvolvimento de dispositivos de segurança e a divulgação dessa segurança na mídia.

A etapa qualitativa possibilitou identificar os construtos e atributos salientes relacionados à utilização de uma nova tecnologia e validar a influência das variáveis do TCPD. A partir da etapa exploratória, foi possível acrescentar ao questionário itens específicos sobre um construto adicional: segurança. Esse construto, não explícito no modelo teórico original, mostrou-se fortemente relevante para os pesquisados nas entrevistas e nos grupos de foco. Por isso, foi operacionalizado no questionário com o objetivo de, posteriormente, fazer parte do teste do modelo, considerando segurança como mais um construto antecedente da intenção comportamental.

\subsection{Fase II: análise multivariada}

Na segunda fase da pesquisa, os dados coletados foram analisados por meio de estatística descritiva, técnicas de análise multivariada de dados e modelagem de equações estruturais (MEE). O uso de técnicas multivariadas nos testes de hipóteses incluiu a análise dos pressupostos correspondentes, conforme recomendações de Hair et al. (2005).

Dentre 600 pessoas amostradas, responderam ao questionário 515 alunos, de 10 instituições de ensino e de 34 cursos de pós-graduação lato sensu.

Para verificar a experiência anterior dos entrevistados com a utilização de outras tecnologias bancárias, buscou-se conhecer os usuários de internet banking, os quais $61,3 \%$ da amostra utilizaram o serviço nos últimos 12 meses. Além da utilização do internet banking, também se investigou a existência de usuários do mobile banking na amostra selecionada. Apenas $5,4 \%$ dos pesquisados utilizam o serviço com frequência, 13,7\% utilizam raramente; e 80,9\% nunca utilizaram. Esse 
item representou também a forma encontrada para mensurar o comportamento real dos indivíduos quanto à utilização da nova tecnologia.

Com relação à percepção da utilização do serviço de mobile banking por parte de parentes, colegas e amigos, 43,6\% da amostra selecionada não soube informar se esses indivíduos de seu convívio utilizam ou não e $27,9 \%$ acreditam que parentes, colegas e amigos utilizam esse serviço.

Após breve caracterização da amostra, procedeu-se à análise descritiva sobre as respostas obtidas. Dentre as variáveis que buscaram medir o construto atitude, facilidade de uso foi a que apresentou índices com maiores médias e menores desvios-padrão (médias acima de 5 e desvio-padrão aproximado de 1,5, em uma escala de 1 a 7).

A respeito do construto norma subjetiva, observou-se que as variáveis que pretendem medi-lo apresentam médias baixas, abaixo de 3 . O mesmo pode ser observado para os construtos segurança e intenção comportamental. Vale ressaltar que intenção comportamental, além de ter apresentado variáveis com médias baixas, apresentou maiores desviospadrão (valores: 2,08; 2,09; 2,07, apresentados nas variáveis que compõem o construto intenção), indicando novamente grande variabilidade das respostas.

Com relação a análise de dados ausentes, foi definido que questionários com dados ausentes superiores a $5 \%$ seriam excluídos da amostra, pois isso afetaria a validade das respostas. Dessa forma, 13 dos 515 questionários tabulados foram excluídos. Após a exclusão, os dados ausentes contabilizados foram 32. O ideal é que esses dados ausentes fossem aleatórios e através de um procedimento sugerido por Hair et al. (2005) pôde-se afirmar que os dados ausentes são ausentes completamente ao acaso (ACAA) ou aleatórios. Realizou-se, então, a substituição deles pelas médias das respectivas variáveis.

Quanto a existência de outliers, observações atípicas nos dados coletados, o critério empregado para diagnosticar outliers univariados foi o proposto por Hair et al. (2005), em que, primeiramente, os dados devem ser convertidos em escores padrões, em que apresentam média 0 (zero) e desvio padrão 1 . Os resultados mostraram 15 casos em que os escores foram superiores a 3, considerados outliers. Todos os casos ocorreram em uma mesma variável, a Q11,"Aprender a usar novas tecnologias geralmente é fácil para mim". Tal resultado foi interpretado como respostas de indivíduos que têm dificuldade em aprender a usar novas tecnologias. Optou-se por retirar essas observações, uma vez que como apresentavam dificuldades em interagir com novas tecnologias, considerou-se que esses indivíduos não faziam parte da amostra deste estudo, constituída por usuários de perfil inovador.

Para a identificação de outliers multivariados empregou-se o critério da distância Mahalanobis ( $\left.D^{2}\right)$, levando em conta um nível de significância de 0,001, considerado conservador por Hair et al. (2005). Com base nesse método, foram encontradas 27 observações atípicas e optou-se por excluílas. Como amostra final, obteve-se 460 observações. 


\subsubsection{Análise dos pressupostos da modelagem de equações estruturais}

Foram realizados testes, objetivando verificar os pressupostos básicos da modelagem de equações estruturais: normalidade, linearidade e homoscedasticidade.

Por problemas de assimetria ou curtose, todas as 26 variáveis violaram o pressuposto de normalidade univariada e, consequentemente, também violam o pressuposto de normalidade multivariada, o que foi confirmado pelo teste do índice de Mardia. Hair et al. (2005) apontam, entretanto, que em estudos com amostras grandes os efeitos negativos da não normalidade tendem a ser menos danosos. Tal argumentação foi considerada e optou-se por prosseguir nas análises previstas, embora se admita que a falta de normalidade das variáveis é mais uma limitação desta pesquisa.

Linearidade dos dados, outro pressuposto para uso da modelagem de equações estruturais, foi verificado analisando-se a matriz de correlações bivariadas das 31 variáveis analisadas. Apesar de terem sido observadas 85 relações não significativas ao nível de $5 \%$, a análise do gráfico de dispersão scaterplot leva à conclusão de que os desvios não alteram a linearidade dos dados.

$\mathrm{Na}$ verificação do pressuposto de homoscedasticidade, o teste $M$ de Box não se mostrou significante ao nível de 0,01 , podendo a amostra ser considerada heteroscedástica (HAIR et al. 2005).

Além dos três pressupostos testados, foram realizadas algumas análises anteriores a aplicação da modelagem de equações estruturais, como multicolinearidade, relativa ao grau de redundância das variáveis (não desejável) e dimensionalidade dos dados, que permite reduzir o conjunto de dados ao menor número possível de fatores e com perda mínima de informação e pode ser identificada por meio de análise fatorial exploratória (AFE) (MALHOTRA, 2001). Com relação a essa última, houve adequação da análise fatorial (por meio dos valores de KMO obtidos, maiores que 0,5 ) e foi então realizada.

Para o construto atitude, a análise fatorial exploratória resultou na distribuição das cargas das variáveis em três fatores, em conformidade com o modelo teórico. Observou-se que as variáveis do construto norma subjetiva apresentaram altas cargas fatoriais e valor de variância explicada considerado alto. Em relação ao construto controle percebido, a análise fatorial exploratória com todas as variáveis apresentou dois fatores. Já o construto segurança, inicialmente, apresentou análise fatorial exploratória com dois fatores. Por entender-se tal construto como unidimensional, retirou-se uma variável. Em relação ao construto intenção comportamental, a análise fatorial exploratória resultou em um único fator, explicando $93,46 \%$ da variância. Os testes demonstraram adequação dos dados e permitiu prosseguimento das análises. 
Mobile banking como novo canal de disseminação de informações e disponibilização de serviços: um teste de Teoria do Comportamento Planejado Decomposto
Deborah Oliveira Santos; Ricardo Teixeira

Veiga; Sarah Ituassú Souza

Procedeu-se à análise da confiabilidade, por meio do método de alfa de Cronbach (a), para verificar se as variáveis resultantes da análise fatorial são consistentes com o que pretendem medir. Optou-se por excluir as variáveis dos construtos com valores de alfa de Cronbach inferiores a 0,6. Foi realizada, portanto, a análise de confiabilidade para cada construto, excluindo variáveis até que o construto ficasse com valores aceitáveis de confiabilidade.

A partir disso, é possível afirmar que todos os construtos e dimensões do estudo possuem valores de confiabilidade altos, acima do limite aceitável. O Quadro 1 apresenta as variáveis que permaneceram na pesquisa e que foram utilizadas nas análises posteriores.

\section{Quadro 1- Variáveis retidas para teste do modelo}

\begin{tabular}{|c|c|c|c|}
\hline Construto & Dimensão & Variável & Pergunta \\
\hline \multirow{9}{*}{$\begin{array}{l}\text { Atitude em Relação } \\
\text { ao Comportamento }\end{array}$} & \multirow{3}{*}{ Utilidade Percebida } & Q6 & $\begin{array}{l}\text { Utilizando o mobile banking poderei fazer minhas transações } \\
\text { bancárias com maior eficiência. }\end{array}$ \\
\hline & & Q7 & $\begin{array}{l}\text { Utilizando o mobile banking ficará mais fácil realizar minhas } \\
\text { transações bancárias. }\end{array}$ \\
\hline & & Q8 & Fazer transações bancárias através do mobile banking é útil. \\
\hline & \multirow{2}{*}{ Facilidade de uso } & Q11 & $\begin{array}{l}\text { Aprender a usar novas tecnologias geralmente é fácil para } \\
\text { mim. }\end{array}$ \\
\hline & & Q12 & $\begin{array}{l}\text { Seria fácil para mim me tornar competente no uso do mobile } \\
\text { banking. }\end{array}$ \\
\hline & \multirow{4}{*}{ Compatibilidade } & Q14 & O mobile banking combina com meu estilo de vida. \\
\hline & & Q15 & $\begin{array}{l}\text { Meus hábitos de comunicação são compatíveis com o uso de } \\
\text { mobile banking. }\end{array}$ \\
\hline & & Q16 & $\begin{array}{l}\text { Minha rotina e condições de trabalho me levam a acessar } \\
\text { serviços bancários pelo celular. }\end{array}$ \\
\hline & & Q17 & $\begin{array}{l}\text { A perspectiva de uso do mobile banking está de acordo com } \\
\text { minha busca por serviços inovadores. }\end{array}$ \\
\hline \multirow[t]{2}{*}{ Norma Subjetiva } & & Q19 & $\begin{array}{l}\text { Caso meus parentes usem o serviço de mobile banking, isso } \\
\text { poderá me influenciar na decisão de utilização desse serviço. } \\
\text { Caso meus amigos ou colegas usem o serviço de mobile } \\
\text { banking, isso poderá me influenciar na decisão de utilização } \\
\text { desse serviço. }\end{array}$ \\
\hline & & Q21 & $\begin{array}{l}\text { Provavelmente, pessoas que são importantes para mim } \\
\text { pensariam que eu deveria usar o mobile banking. }\end{array}$ \\
\hline \multirow{2}{*}{$\begin{array}{l}\text { Controle } \\
\text { Comportamental } \\
\text { Percebido }\end{array}$} & \multirow[b]{2}{*}{ Tecnologia } & Q25 & $\begin{array}{l}\text { Acredito que através do celular que possuo atualmente } \\
\text { poderei realizar transações bancárias. }\end{array}$ \\
\hline & & Q27 & $\begin{array}{l}\text { Tenho condições de adquirir um aparelho de celular } \\
\text { compatível com a tecnologia necessária para usar o mobile } \\
\text { banking. }\end{array}$ \\
\hline \multirow[b]{2}{*}{ Segurança } & & Q30 & Acredito que o sistema de mobile banking é seguro. \\
\hline & & Q31 & $\begin{array}{l}\text { É mais seguro usar o celular que a internet para realizar } \\
\text { transações bancárias. }\end{array}$ \\
\hline \multirow{3}{*}{ Intenção } & & Q34 & $\begin{array}{l}\text { Eu tenho a intenção de realizar transações bancárias } \\
\text { utilizando o telefone celular nos próximos } 12 \text { meses. }\end{array}$ \\
\hline & & Q35 & Eu desejo usar o mobile banking nos próximos 12 meses. \\
\hline & & Q36 & Eu planejo ser um usuário de mobile banking. \\
\hline
\end{tabular}

Fonte: Elaborado pelos autores. 


\section{Apresentação dos resultados}

Após a realização das análises sobre os pressupostos para a modelagem de equações estruturais (MEE) procedeu-se o teste do modelo, por meio do software AMOS 4.0. Segundo Hair et al. (2005), a MEE possibilita ao pesquisador estimar os efeitos estabelecidos entre as variáveis e testar se o modelo utilizado é consistente com os dados observados. A seguir, apresenta-se o modelo testado após a verificação de seus pressupostos (Fig. 2).

Figura 2 - Resultado do modelo testado

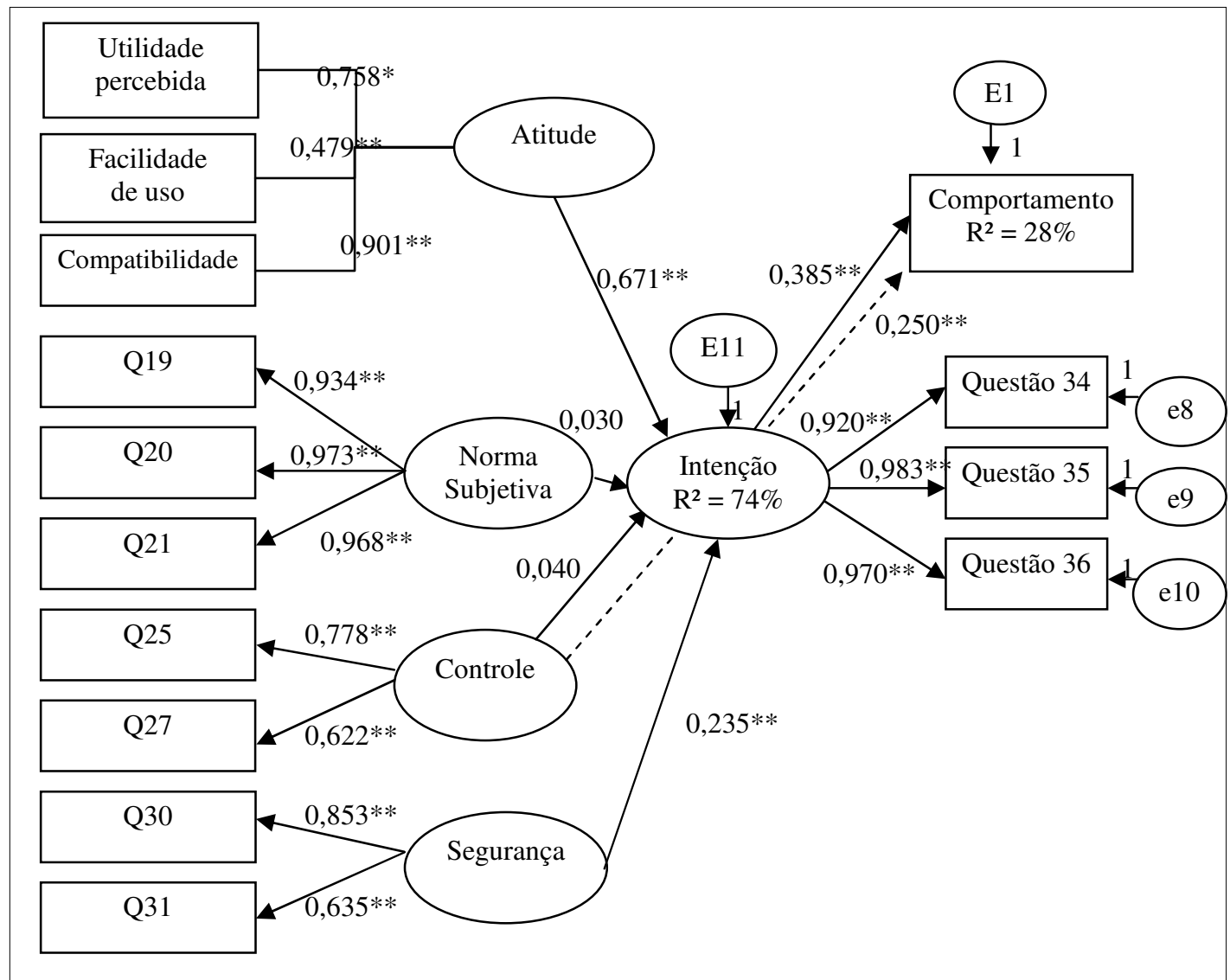

Fonte: Elaborado pelos autores.

Após a avaliação do ajuste do modelo, através da análise dos ajustes absoluto e parcimonioso, constatou-se que ele é uma representação adequada do conjunto inteiro de relações causais. A partir disso pôde-se verificar se as hipóteses de pesquisa foram ou não atendidas.

A hipótese $1(\mathrm{H} 1)$ estabelece que "Há um relacionamento positivo entre os construtos atitude e intenção comportamental" e foi confirmada nesta pesquisa. De fato, a atitude foi responsável pelo maior impacto em intenção, com uma carga de 0,671.

Com relação ao teste da hipótese $2(\mathrm{H} 2)$, "Há um relacionamento positivo entre os construtos normas subjetivas e intenção comportamental", verificou-se que essa relação não foi sustentada neste 
trabalho. Norma subjetiva apresentou valores não significativos para a explicação da intenção comportamental.

A explicação para o valor não significativo da norma subjetiva, possivelmente, deve-se ao baixo impacto que as pressões sociais exercem nos indivíduos inovadores. Esses, geralmente, apresentam perfil pioneiro em relação a inovações, sendo, portanto, menos sensíveis a influências de amigos e parentes para a utilização do mobile banking. Além disso, verificou-se, durante a etapa de pesquisa exploratória, que poucos eram os participantes que conheciam pessoas que utilizavam a nova tecnologia. Por esse motivo, dificilmente alguém agiria no sentido de influenciar a intenção de uso do novo sistema.

A hipótese 3 (H3), "Há um relacionamento positivo entre os construtos controle percebido e intenção comportamental", não foi sustentada. $\mathrm{O}$ construto controle percebido apresentou-se não significante. Esse resultado pode estar relacionado ao fato de que, por mais que um indivíduo tenha condições de adquirir um aparelho de celular compatível com a tecnologia necessária para usar o mobile banking, a intenção em utilizá-lo dependerá em maior parte de seu perfil inovador do que propriamente dos recursos tecnológicos oferecidos pelo celular.

A hipótese $4(\mathrm{H} 4)$, "Há um relacionamento positivo entre os construtos segurança e intenção comportamental", foi suportada, porém segurança impacta intenção em menor proporção que atitude, com carga de 0,235 .

A FIG. 2 mostra que o efeito combinado dos construtos significantes do modelo (atitude em relação ao comportamento e segurança) é responsável pelas variações encontradas em intenção. Assim, ao analisar o $\mathrm{R}^{2}$ geral do modelo (variância explicada), percebe-se um valor alto, de 0,74 , o que indica que os construtos significantes do modelo são capazes de explicar $74 \%$ da variância da intenção. Apesar desse índice, considerado satisfatório, o resultado obtido não sustenta a hipótese 5 (H5) deste estudo: "A teoria do comportamento planejado decomposto possui poder explicativo para a adoção de novas tecnologias pelos consumidores." Essa hipótese não pôde ser confirmada devido ao fato de que para este estudo houve alterações no modelo em comparação com o utilizado pelos autores Taylor e Todd (1995). Dos três construtos apresentados pela TCP decomposto (atitude, normas subjetivas e controle percebido), apenas um - atitude - mostrou-se significativo para explicar intenção comportamental. Além disso, também foi incluído outro construto - segurança -, que se apresentou significante, mas não estava previsto no modelo original.

Uma relação comprovada foi entre os construtos controle percebido e comportamento real. Apesar de controle percebido não possuir impacto significativo na intenção, afeta significativamente o comportamento real dos indivíduos. Essa relação demonstra que a hipótese 6 (H6) foi confirmada: "Há um relacionamento positivo entre os construtos controle percebido e comportamento real". 
Outra relação analisada neste estudo foi entre intenção e comportamento real, este último medido pelo item Q3 do questionário ("Você utiliza o serviço de mobile banking: (1) Nunca, (2) Utilizo raramente, (3) Utilizo freqüentemente"). Essa questão foi considerada como indicativo do comportamento real dos indivíduos pesquisados. Dessa forma, a significância da relação comprova as proposições teóricas de que intenção comportamental é antecedente do comportamento real e sustenta a hipótese 7 (H7) desta pesquisa: "Há um relacionamento positivo entre os construtos intenção comportamental e comportamento real".

Como consequência dos resultados de $\mathrm{H} 6 \mathrm{e} \mathrm{H7}$, mediu-se o valor de $\mathrm{R}^{2}$ de explicação do comportamento. O resultado, apresentado na FIG. 2, indica que os dois construtos (controle percebido e intenção) são capazes de explicar $28 \%$ da variação do comportamento real do indivíduo. Esse baixo valor obtido talvez esteja relacionado à forma de medição do comportamento real. A questão utilizada para medí-lo avaliou apenas os usuários ou não no momento da pesquisa. Como ainda não há uma ampla base de pessoas que usam o novo sistema, a informação obtida pode ser incompatível com o comportamento real dos indivíduos se medido alguns meses após o preenchimento do questionário, período em que seria mais apropriada a mensuração do comportamento real.

A partir da análise das medidas de qualidade de ajuste, é possível considerar os resultados obtidos neste estudo como uma representação aceitável dos construtos teorizados. É possível afirmar, portanto, que grande parte da variação do construto intenção deve-se à atitude, em suas três dimensões abrangidas neste estudo: utilidade percebida, facilidade de uso e compatibilidade.

\section{Considerações finais}

Devido às recentes revoluções tecnológicas, a informação vem assumindo um papel cada vez mais importante na vida das pessoas ao redor do mundo. Além disso, tem revolucionado o modo como produtos e serviços são comercializados (CARVALHO, 2004).

Assim sendo, é fato que as várias definições da sociedade atual parecem convergir para o fato de que os gerenciamentos da informação e do conhecimento passaram a se constituir nos diferenciais competitivos (VITAL, 2006). Isso justifica o crescimento do interesse e investimento das organizações nas novas interfaces de comunicação com o cliente e em novas formas de comercialização de produtos e serviços.

Por isso, as principais tendências do setor apontam para o crescimento dos investimentos em TI e o consequente avanço no segmento do banco virtual. Dessa forma, faz sentido a criação do mobile banking, um canal de distribuição de serviços bancários via telefone celular.

$\mathrm{Na}$ perspectiva dos clientes, existem fatores favoráveis e desfavoráveis à adoção dessas inovações. Segundo participantes da 
pesquisa da fase qualitativa, a comodidade é um fator essencial à formação de uma atitude favorável à utilização da nova tecnologia. Um dos principais desafios, porém, consiste em vencer a resistência que alguns clientes podem desenvolver em relação ao uso da tecnologia, principalmente no que se refere à percepção de confiabilidade das operações. Ademais, segurança parece ser um fator-chave para o sucesso e difusão dessa nova mídia. Aliás, Carvalho (2004) já ressaltava a importância de se considerar os aspectos de segurança e privacidade das informações que trafegam pelas redes de comunicação.

Na fase II de pesquisa, de natureza quantitativa, em que se obteve um número maior de participantes (515), foi alcançado objetivo de explicitar os fatores que agem no sentido de influenciar as pessoas na formação da intenção de uso do mobile banking como novo canal de interação com o banco. Buscou-se verificar a adequação da teoria do comportamento planejado decomposto para explicar a intenção do consumidor de utilizar o mobile banking.

Dos três construtos apresentados pela TCP decomposto (atitude, normas subjetivas e controle percebido), apenas um - atitude apresentou impacto significativo na intenção comportamental. Foi incluído no modelo um quarto construto - segurança -, que também se apresentou significante. O percentual expressivo de variação explicada pelo modelo ( $74 \%$ da variação na intenção comportamental) deve-se a variações na atitude e na percepção de segurança da nova tecnologia e ressalta a importância do referencial teórico utilizado.

Outro resultado relevante deste trabalho foi a obtenção de moderada evidência de associação da intenção comportamental e controle percebido com o comportamento real dos indivíduos de adoção do mobile banking $\left(\mathrm{R}^{2}=0,28\right)$.

Além disso, o pressuposto de vários modelos comportamentais foi também validado: intenção comportamental antecede comportamento real e controle percebido impacta diretamente o comportamento real. Isso demonstra que a TCP decomposto apresentou, na amostra estudada, sustentação empírica no contexto de adoção de tecnologias bancárias, especificamente mobile banking.

Os resultados deste trabalho podem trazer importantes implicações teóricas e práticas. A contribuição deste estudo para a academia diz respeito à aplicação da teoria do comportamento planejado decomposto no contexto brasileiro e para fins de estudar o comportamento relacionado à adoção de nova tecnologia e novo canal de disseminação de informações e realização de serviços bancários. Quanto às implicações gerenciais, percebe-se que os elementos validados pela teoria podem ser utilizados pelas instituições para ajudá-las na condução dos negócios e para dirigir campanhas de marketing com foco nos reais aspectos influenciadores de uma decisão. Alguns fatores significativos que podem influenciar a adoção do mobile banking, de acordo com a amostra deste estudo: a) oferecer interfaces que propiciem facilidade de uso; b) aperfeiçoar a disponibilidade do sistema e divulgar as vantagens do serviço, demonstrando como ele se 
adapta ao estilo de vida e trabalho das pessoas; e c) aprimorar e divulgar as características de privacidade e segurança.

Dentre as limitações da pesquisa, destaca-se que os resultados obtidos não podem ser vistos como conclusivos, pois se trata de pesquisa baseada em amostragem não-probabilística. Outra provável limitação importante é que, apesar da amostra escolhida se assemelhar ao perfil de inovadores, não se pode garantir que a amostra estudada seja a melhor representação desse segmento. Replicações desta pesquisa deveriam basear-se em amostras verdadeiramente probabilísticas e em metodologias de segmentação que identificassem consumidores inovadores com maior precisão.

\section{Referências}

ABDALA, R. A. Avaliação dos fatores que influenciam a decisão de utilização dos serviços bancários através de internet na cidade de Belo Horizonte. 2004. 120f. Dissertação (Mestrado em Engenharia de Produção) - Programa de Pós Graduação em Engenharia de Produção, Universidade Federal de Santa Catarina, Florianópolis, 2004.

AJZEN, I. Constructing a TPB questionaire: conceptual and methodological considerations. [S. I.: S. n.], 2002. Disponível em: <http://wwwunix.oit.umass.edu/ raizen/>. Acesso em: 13 nov. 2006.

AJZEN, I. From intentions to actions: a theory of planned behavior. In: KUHI, J.; BECKMAN, J. Action - control: from cognition to behavior. Heidelberg: Springer, 1985.

ALBERTIN, A. L. Modelo de comércio eletrônico e um estudo no setor bancário. RAE- Revista de Administração de Empresas, São Paulo, v. 39, n.1, p.64-76, jan./mar. 1999.

BARDIN, L. Análise de Conteúdo. Lisboa: Edições 70, 2004.

BRASIL, V. S. Sistemas de entrega de serviços bancários: variáveis antecedentes e características individuais influenciadoras do uso de canais de atendimento "interpessoal" e "internet". In: ENANPAD, 30., 2006, Salvador. Anais... Salvador: ANPAD, 2006. CD-Rom.

BROWN, M. E. A general model of information-seeking behavior. Proceedings of the American Society for information Science, v. 2, p. 9$14,1991$.

CARVALHO, S. Os bens de informação e o problema da primeira cópia. RAE- Revista de Administração de Empresas, v. 44, ed. esp. Minas Gerais, p. 97-107, 2004.

CHAIM, R. M. Comércio eletrônico ou canal de vendas eletrônico? Perspect. Ciência da Informação, Belo Horizonte, v. 5, n. 1, p. 69-79, jan./jun. 2000.

ENGEL, J. F.; BLACKWELL, R. D.; MINIARD, P. W. Consumer Behavior. $8^{a}$ ed. Philadelphia: Dryden Press, 1995. 
FEDERAÇÃO BRASILEIRA DE BANCOS DE AUTOMAÇÃO BANCÁRIA FEBRABAN. [Automação Bancária]. [S.l: s.n.], 2008. Disponível em: <http://febraban.org.br/automação.asp>. Acesso em: 10 jan. 2008.

FERREIRA, S. M. S. P. Novos paradigmas e novos usuários de informação. Ciência da Informação, Belo Horizonte, v. 25, n. 2, p. 217-223, 1995.

FIGUEIREDO, N. M. Informação como ferramenta para o desenvolvimento. Ciência da Informação, Belo Horizonte, v. 19, n. 2, p. 123-129, jul./dez. 1990.

GODOY, A. Pesquisa qualitativa: tipos fundamentais. Revista de Administração de Empresa, São Paulo, v. 35, n. 3, p. 20-29, maio/jun. 1995.

HAIR, J. et al. Análise multivariada de dados. $5^{a}$ ed. Porto Alegre: Bookman, 2005.

HERNANDEZ, J. M. C; MAZZON, J. A. Adoção de Internet Banking: proposição e aplicação de uma abordagem metodológica integrada. In: ENANPAD, 30., 2006, Salvador. Anais... Salvador: ANPAD, 2006. CD-Rom.

MACMULLIN, S. E.; TAYLOR, R. S. Problem dimensions and information traits. The information Society, v. 3, n.1, p. 91-111, 1984.

MALHOTRA, N. K. Pesquisa de marketing: uma orientação aplicada. $3^{a}$ ed. Porto Alegre: Bookman, 2001.

MORIGI, V. J.; PAVAN, C. Tecnologias de informação e comunicação: novas sociabilidades nas bibliotecas universitárias. Ci. Inf., Brasília, v. 33, n. 1, p. 117-125, jan./abril 2004.

PEREIRA, D. S.; PAULA, G. M. Inovações tecnológicas, mudança no aparato regulatório e estratégia empresarial: o caso da CTBC Celular. In: ENANPAD, 25., 2001, Campinas. Anais... Campinas: ANPAD, 2001. CDRom.

ROGERS, E. M. Diffusion of Innovations. New York: The Free Press, 1983.

ROUSE, W. B.; ROUSE, S. H. Human information seeking and design of information systems. Information Processing and Management, v. 20, $\mathrm{n}$. 1-2, p. 129-38, 1984.

SOLOMON, M. R. O comportamento do consumidor: comprando, possuindo e sendo. $5^{\mathrm{a}}$ ed. Porto Alegre: Bookman, 2002.

SOUZA, R.V. Prontidão para tecnologia do consumidor: aspectos emocionais da adoção de produtos e serviços baseados em tecnologia. In: ENANPAD, 30., 2006, Salvador. Anais... Salvador: ANPAD, 2006. CD-Rom.

TAYLOR, S.; TODD, P. A. Understanding information technology usage: a test of Competing Models. Information Systems Research, v. 6, n. 2, p. 144-176, 1995.

VITAL, L. P. Fontes e canais de informação utilizados no desenvolvimento de sistemas em empresa de base tecnológica. Revista ACB: 
Mobile banking como novo canal de disseminação de informações e disponibilização de serviços: um teste de Teoria do Comportamento Planejado Decomposto
Deborah Oliveira Santos; Ricardo Teixeira

Veiga; Sarah Ituassú Souza

Biblioteconomia em Santa Catarina. Florianópolis, v. 11, n. 2, p. 297-313, ago./dez. 2006. 